\title{
Virologic End Of Treatment Response
}

National Cancer Institute

\section{Source}

National Cancer Institute. Virologic End Of Treatment Response. NCI Thesaurus. Code C120601.

A finding of aviremia at the end of the planned or actual end of treatment period. 